\title{
Hypocalcemia: What a Surgeon should know
}

\author{
${ }^{1}$ Anish Kolly, ${ }^{2}$ Vijaya Sarathi, ${ }^{3}$ Sapana Bothra, ${ }^{4}$ Aromal Chekavar, ${ }^{5}$ Mayilvaganan Sabaretnam, ${ }^{6}$ Amit Agarwal
}

\begin{abstract}
Hypocalcemia is one of the sequelae following thyroidectomy (TT) and becomes a complication when it becomes permanent. Parathyroid preservation is a crucial step in the skillful operative procedure of TT. When due care is not taken, the surgeon and the treating physician are faced with the issue of treating the dreaded complication of permanent hypocalcemia. In this article, we address the issue of hypocalcemia following thyroid surgery and its management.
\end{abstract}

Keywords: Hypocalcemia, Parathyroid, Thyroidectomy.

How to cite this article: Kolly A, Sarathi V, Bothra S, Chekavar A, Sabaretnam M, Agarwal A. Hypocalcemia: What a Surgeon should know. World J Endoc Surg 2017;9(2):72-77.

Source of support: Nil

Conflict of interest: None

\section{INTRODUCTION}

Hypocalcemia is one of the most dreaded complications after surgery of the thyroid and parathyroid glands. Hypocalcemia, especially when permanent, leads to significant impairment in the quality of life and is associated with a range of deleterious effects on general health. It is thus imperative that the operating surgeon understands the risk of hypocalcemia postsurgery and tries to minimize the risk of postoperative hypocalcemia by taking necessary pre-, intra-, and postoperative measures. With the recent surge in ambulatory thyroid surgery, which allows for the early discharge of patients, postoperative hypocalcemia becomes an even more important consideration.

\section{PREVALENCE}

The reported prevalence of hypocalcemia after thyroid surgery ranges from 0.3 to $66.2 \% .^{1-4}$ The lack of a consistent definition for hypocalcemia, differences in the extent

\footnotetext{
1,3,4 Senior Resident, ${ }^{2}$ Associate Professor, ${ }^{5}$ Assistant Professor ${ }^{6}$ Professor

1,2Department of Endocrinology, Vydehi Institute of Medical Sciences and Research Centre, Bengaluru, Karnataka, India

${ }^{3-6}$ Department of Endocrine Surgery, Sanjay Gandhi Postgraduate Institute of Medical Sciences, Lucknow, Uttar Pradesh, India

Corresponding Author: Mayilvaganan Sabaretnam, Assistant Professor, Department of Endocrine Surgery, Sanjay Gandhi Postgraduate Institute of Medical Sciences, Lucknow, Uttar Pradesh, India, Phone: +915222495424, e-mail: drretnam@ gmail.com
}

of surgery, and differences in indication for surgery across studies contribute to this wide variability. ${ }^{5}$ On the contrary, the risk of permanent postoperative hypocalcemia, which is defined as persistence of hypocalcemia even after 12 months of cervical surgery, has been reported to range from 0.6 to $12.1 \% .^{6-9}$

\section{ETIOPATHOGENESIS}

The cause of hypocalcemia after thyroid surgery is multifactorial. ${ }^{10}$ Hypoparathyroidism seen after surgery can be due to iatrogenic surgical trauma to the parathyroid glands or its blood supply or inadvertent removal of parathyroid glands. Depending on the extent of parathyroid gland damage, hypocalcemia may be transient, resolving within a few months, or permanent, in which the patient would require lifelong calcium and vitamin D supplementation. The nonhypoparathyroidism-related causes of postoperative hypocalcemia include hungry bone syndrome, a condition typically encountered postoperatively in long-standing cases of hyperparathyroidism and hyperthyroidism, characterized by excess uptake of calcium by the bones. ${ }^{11,12}$ Few studies have implicated calcitonin release as a cause of postoperative hypocalcemia; however, its role is controversial. ${ }^{13}$ Hypocalcemia can also be due to hemodilution resulting from excess postoperative fluid replacement, which is also associated with increased calcium excretion. ${ }^{14}$

\section{RISK FACTORS}

The factors that predict the risk of postoperative hypocalcemia include the extent of surgery, concomitant lymph node dissection, surgery for retrosternal goiter, the experience of the surgeon, the number of functioning parathyroid glands left behind, and hyperthyroidism. ${ }^{9}$

Hypocalcemia is traditionally believed to be more frequently encountered in cases undergoing total TT as compared with relatively minor resections of the thyroid gland. ${ }^{15,16}$ This is expected since the more extensive surgeries are associated with a higher risk of manipulation of the parathyroid glands and their blood supply. Patients undergoing surgery for thyroid malignancies may have an additionally increased risk due to altered anatomy and often concomitantly performed lymph node dissection. ${ }^{17}$ Surgeries for retrosternal goiter are also associated with frequent occurrence of injury to parathyroid glands and increased risk of hypocalcemia. ${ }^{18}$ Following thyroidectomy 
reduction of calcium due to decreased renal tubular reabsorption of calcium was thought to be a factor. ${ }^{19}$

Another condition, i.e., associated with increased risk of hypocalcemia is Graves' disease. ${ }^{20-22}$ The risk of hypocalcemia after TT has been reported to be 20 times higher with Graves' disease as compared with that of TT for a nontoxic multinodular goiter (MNG). ${ }^{23,24}$ Hyperthyroidism is associated with increased bone resorption, due to which excess calcium is released into the blood pool. This, in turn, suppresses the parathyroid hormone (PTH) levels leading to transient hypoparathyroidism and hypocalcemia in the postoperative period. Patients with hyperthyroidism are also at risk of hungry bone syndrome due to increased bone formation once the hyperthyroidism is controlled. Surgeries performed for Graves' disease are associated with more frequent hypocalcemia as compared with that for toxic MNG patients. ${ }^{18}$ This may be due to the role of autoimmunity as suggested by the increased occurrence of postoperative hypocalcemia with other autoimmune thyroid disorders like Hashimoto thyroiditis. ${ }^{25}$

Surgical techniques employed during the procedure may also have implications for the risk of postoperative hypocalcemia. The ligation of the inferior thyroid artery (ITA) is associated with a greater risk of hypocalcemia as compared with ligation of the tertiary branches. ${ }^{7}$ Studies have also demonstrated that vasculature-preserving techniques reduce the risk of postoperative hypocalcemia. ${ }^{26}$

Most experts believe that the surgeon's skill and experience can affect the occurrence of postoperative hypocalcemia. ${ }^{27}$ Indeed, this was first evident when patients who underwent TT by Theodor Kocher, using his principles of bloodless surgery, had a lesser incidence of postoperative hypocalcemia as compared with those operated by Billroth. ${ }^{28}$ However, a recent study found that patients operated by surgical trainees had complications that were comparable to patients operated on by consultant surgeons. ${ }^{29}$

\section{CLINICAL FEATURES}

The symptoms of hypocalcemia usually manifest 24 to 48 hours after surgery. ${ }^{30}$ Clinically, the patients can present with muscle cramps, perioral and peripheral paresthesias, carpopedal spasm or tetany, and confusion. However, more often, the patient is asymptomatic and the presence of mild hypocalcemia can only be detected biochemically. In patients with mild hypocalcemia, Chvostek's sign and Trousseau's sign may be positive. Chvostek's sign is elicited by tapping over the area of the facial nerve to look for twitching of facial muscles. Trousseau's sign is elicited by inducing pressure to the upper arm above the systolic pressure for 3 minutes, using a sphygmomanometer, to look for carpopedal spasm resulting from ischemia. Chvostek's sign is absent in about one-third of patients with hypocalcemia and can also be noticed in $10 \%$ of persons with normal calcium levels. However, Trousseau's sign is more sensitive and specific and is present in $94 \%$ of patients with hypocalcemia, while in only $1 \%$ of persons with normal calcium levels.

\section{DIAGNOSIS}

In patients with hypoalbuminemia, corrected serum Calcium should be estimated by using the formula: corrected serum calcium in $\mathrm{mg} / \mathrm{dL}=$ observed serum calcium in $\mathrm{mg} / \mathrm{dL}+(4-$ serum albumin in $\mathrm{g} / \mathrm{dL})$ multiplied by a factor 0.8 . Hypocalcemia is classically described as serum calcium less than the lower limit of normal for the assay. A recent American association of clinical endocrinologists guideline defines hypocalcemia as serum calcium (adjusted to serum albumin of $4 \mathrm{gm} / \mathrm{dL}$ ) less than $8.5 \mathrm{mg} / \mathrm{dL}$.

There is no consensus about the optimal postoperative time to determine the serum calcium level. Regular monitoring of serum calcium twice daily may be the preferred approach. In patients having hypocalcemic symptoms but normal serum calcium levels, ionic calcium should be estimated. Serum magnesium should be evaluated in patients with refractory hypocalcemia. High or normal serum phosphorus suggests hypoparathyroidism, whereas low phosphorus suggests hungry bone syndrome.

\section{PREDICTORS OF POSTOPERATIVE HYPOCALCEMIA}

With the recent increase in day-care thyroid surgeries, prediction of postoperative hypocalcemia is important to facilitate early discharge. Discharging patients on calcium supplementation has been endorsed by some surgeons as a means to reduce symptomatic hypocalcemia, while others have advocated sending patients home with prescriptions for calcium supplementation to be taken in case symptoms of hypocalcemia develop. However, both these approaches have been contested. Several studies have been carried out to determine factors that predict postoperative hypocalcemia in patients undergoing TT to enable more selective postoperative surveillance and management as per the patient's risk in a bid to avoid unnecessary risk of iatrogenic hypercalcemia and to reduce the burden of inpatient stay.

Intraoperative or postoperative serum PTH levels have been proposed to be early predictors of the development of postoperative hypocalcemia after TT. The sensitivity of intraoperative serum PTH levels in predicting postoperative hypocalcemia has been reported to range from 70 to $80 \% .^{31-33}$ The predictive value of PTH can be improved by 
testing postsurgery. Using various cutoffs and different testing times, the sensitivity and specificity of 1 hour to 1 day postoperative intact PTH (iPTH) levels less than 6 to $35 \mathrm{pg} / \mathrm{mL}$ have been reported to range from 69 to $100 \%$ and 81 to $100 \%$ respectively. ${ }^{9,34-36}$ In recent studies, fall in postoperative iPTH levels as compared with preoperative iPTH has been suggested to have better predictive values. A fall in iPTH by $62 \% 2$ hours postsurgery has shown to have a sensitivity and specificity of $100 \%$ in predicting the risk of subsequent hypocalcemia. ${ }^{37}$ In another novel study, iPTH levels in the surgical site irrigation fluid of greater than $250 \mathrm{pg} / \mathrm{mL}$ conferred a 69-fold increased risk of postoperative hypocalcemia. ${ }^{38}$ Though there are numerous studies on utilization of iPTH levels in the prediction of postoperative hypocalcemia, routine use of such measurements is yet to be advocated as standard of care.

The presence of low preoperative serum 25-hydroxy vitamin D (25-OHD) levels has also been reported to be associated with increased risk of postoperative hypocalcemia in patients who undergo TT. In a study by Erbil et $\mathrm{al}^{39}$ the presence of serum 25-OHD levels less than $25 \mathrm{ng} / \mathrm{mL}$ (62.5 nmol/L) predicted 15 times increased risk for postoperative hypocalcemia in patients who had undergone TT for nontoxic MNG. Vitamin D deficiency may also decrease the negative predictive value of intraand postoperative iPTH to predict hypocalcemia.

Monitoring of serum calcium postsurgery may seem a more cost-effective option. However, hypocalcemia usually manifests 1 to 2 days after surgery. Hence, this approach may miss many patients with hypocalcemia if the patients are getting discharged on the first or second day of surgery. It is a common practice in a few centers to do daily calcium testing postsurgery until a rising trend in calcium values is observed. A drop in serum calcium levels on postoperative day 1 of more than $1.1 \mathrm{mg} / \mathrm{dL}$ as compared with the immediate preoperative levels was shown to have good sensitivity in detecting subsequent hypocalcemia. ${ }^{40}$ In another study, the slope of change between total calcium between 8 th and 14th postoperative hour in hypocalcemic patients was found to be significantly steeper than normocalcemics, and hence a trend of fall in calcium in consecutive samples was suggestive of predicting further hypocalcemia. ${ }^{41}$

\section{PREOPERATIVE STRATEGIES TO PREVENT POSTOPERATIVE HYPOCALCEMIA}

Vitamin D status may be evaluated preoperatively. If serum 25-OHD level is less, adequate replacement with cholecalciferol (60,000 IU once weekly for 4-8 weeks) should be considered. ${ }^{42}$ In patients with unknown vitamin D status, empirical vitamin D replacement may still be considered. Although this may hopefully decrease the rates of postoperative hypocalcemia, this has not been documented in clinical trials. ${ }^{42}$ Care should be taken not to worsen hypercalcemia in undiagnosed patients with primary or tertiary hyperparathyroidism.

\section{INTRAOPERATIVE STRATEGIES TO PREVENT POSTOPERATIVE HYPOCALCEMIA}

For any disease, prevention is always better than cure. Understanding the parathyroid anatomy and performing meticulous dissection goes a long way in preventing postoperative hypoparathyroidism. During TT, at least one parathyroid gland should be identified and an attempt should be made to identify and preserve as many parathyroid glands; each identified parathyroid gland should be treated as the only remaining functional gland and dissected with care (" $1+X^{\prime \prime}$ principle). ${ }^{43}$ Use of nanocarbon particles may help avoid inadvertent removal of the parathyroid glands, thereby reducing postoperative hypoparathyroidism and hypocalcemia. ${ }^{44}$ It is equally important to preserve the vascularity of the parathyroid glands. Inferior thyroid artery truncal ligation is commonly practiced during TT. Although the ITA supplies only one-third of the blood supply to the parathyroids, few studies have reported increased rates of hypocalcemia with truncal ITA ligation. ${ }^{7,26}$ Halsted's "capsular dissection" with ligation of the tertiary branches of ITA is a viable alternative to prevent complications. ${ }^{45}$ Use of electrothermal bipolar vessel sealer (Ligasure) or ultrasonic devices (harmonic focus)may be helpful in reducing postoperative temporary hypocalcemia. ${ }^{46,47}$

During the surgery, if a parathyroid gland is accidentally excised or devascularized, the standard of care is to autotransplant the gland in situ. However, successful revascularization of the autotransplanted gland can take up to 8 weeks, with many patients developing transient hypocalcemia during this period.

\section{MANAGEMENT}

The management of hypocalcemia should be guided by clinical features and biochemical severity of hypocalcemia. Hypocalcemia acts as a stimulus for PTH secretion and hastens parathyroid function recovery. Thus, in patients planned for longer hospital stay and mild hypocalcemia, treatment can be withheld and the patient is observed for clinical or biochemical worsening.

Intravenous (IV) 10\% calcium gluconate is the preferred route of calcium administration in cases of severe hypocalcemia with symptoms. Calcium gluconate is preferred over calcium chloride for IV use since the former is associated with less irritation and less tissue necrosis in the event of extravasation into the subcutaneous space. Calcium gluconate is given as an infusion in 5\% 
dextrose or normal saline, the former being preferred as sodium-containing fluids can increase the osmotic load, thereby increasing the calcium excretion by the kidney. In case of tetany, $10 \mathrm{~mL}$ of $10 \%$ calcium gluconate can be administered over 10 minutes followed by continuous infusion. Patients should also be concomitantly initiated on oral calcium and vitamin D analogs. In patients with mild to moderate hypocalcemia, oral calcium and/ or vitamin D analogs may be the initial therapy. All patients with hypocalcemia should be evaluated with serum magnesium and those with serum magnesium $<1.6 \mathrm{mg} / \mathrm{dL}$ should be supplemented with magnesium.

The supplementation of oral calcium alone is not effective, most often in patients with moderate to severe hypoparathyroidism. In patients with hypoparathyroidism, insufficiency of PTH leads to decreased formation of the active $1,25(\mathrm{OH})_{2}$ vitamin $\mathrm{D}$ (calcitriol), which mediates the effect of PTH on intestinal calcium reabsorption. Hence, it is beneficial to administer calcitriol or other 1-alpha hydroxylated vitamin D analogs to patients with hypoparathyroidism. The calcemic action of calcitriol can last more than 24 hours after a single dose of the drug. The typical initial dose of calcitriol is 0.25 to $0.5 \mu \mathrm{g}$ twice daily. Alfacalcidol (1alpha-hydroxyvitamin D) can also be used at doses twice that of calcitriol, but the time to offset of action is longer. The increase in the serum calcium typically follows 1 to 3 days after treatment. If not adequately replaced preoperatively, 60,000 IU of oral cholecalciferol should be given for 8 weeks followed by a maintenance dose (1000-2000 U/day or 60,000 IU once a month).

In patients receiving levothyroxine (LT4), calcium tablets should be given at a minimum gap of 4 hours to avoid interference with LT4 absorption. Care should be exercised in patients receiving proton pump inhibitors since acidic $\mathrm{pH}$ in the stomach is required for the absorption of calcium carbonate. In such patients, use of calcium citrate may be more appropriate.

In the long run, treatment by synthetic (1-84) PTH confers the added advantage of preventing hypercalciuria and subsequent renal calculi and allows for decreasing the dosage of calcium and calcitriol supplementation. Although approved by the Food and Drug Administration, its use is limited due to high cost and limited availability. ${ }^{1-34}$ A PTH administered in twice-daily doses is a suggested alternative with satisfactory results. Prophylactic use of teriparatide has also been reported in TT patients at risk for hypoparathyroidism. In the recent THYPOS trial, in patients with 4-hour postoperative iPTH $<10 \mathrm{pg} / \mathrm{mL}$, use of teriparatide $20 \mu \mathrm{g}$ twice a day till discharge reduced the incidence of hypocalcemia and the need for calcium supplementation after 1 month. ${ }^{48}$ Recently, teriparatide infusion was found to provide less fluctuation in serum calcium levels and better efficacy in reduction of hypercalciuria (Flow Chart 1). ${ }^{49}$

Flow Chart 1: Depicting monitoring and treatment of a postoperative patient after total thyroidectomy

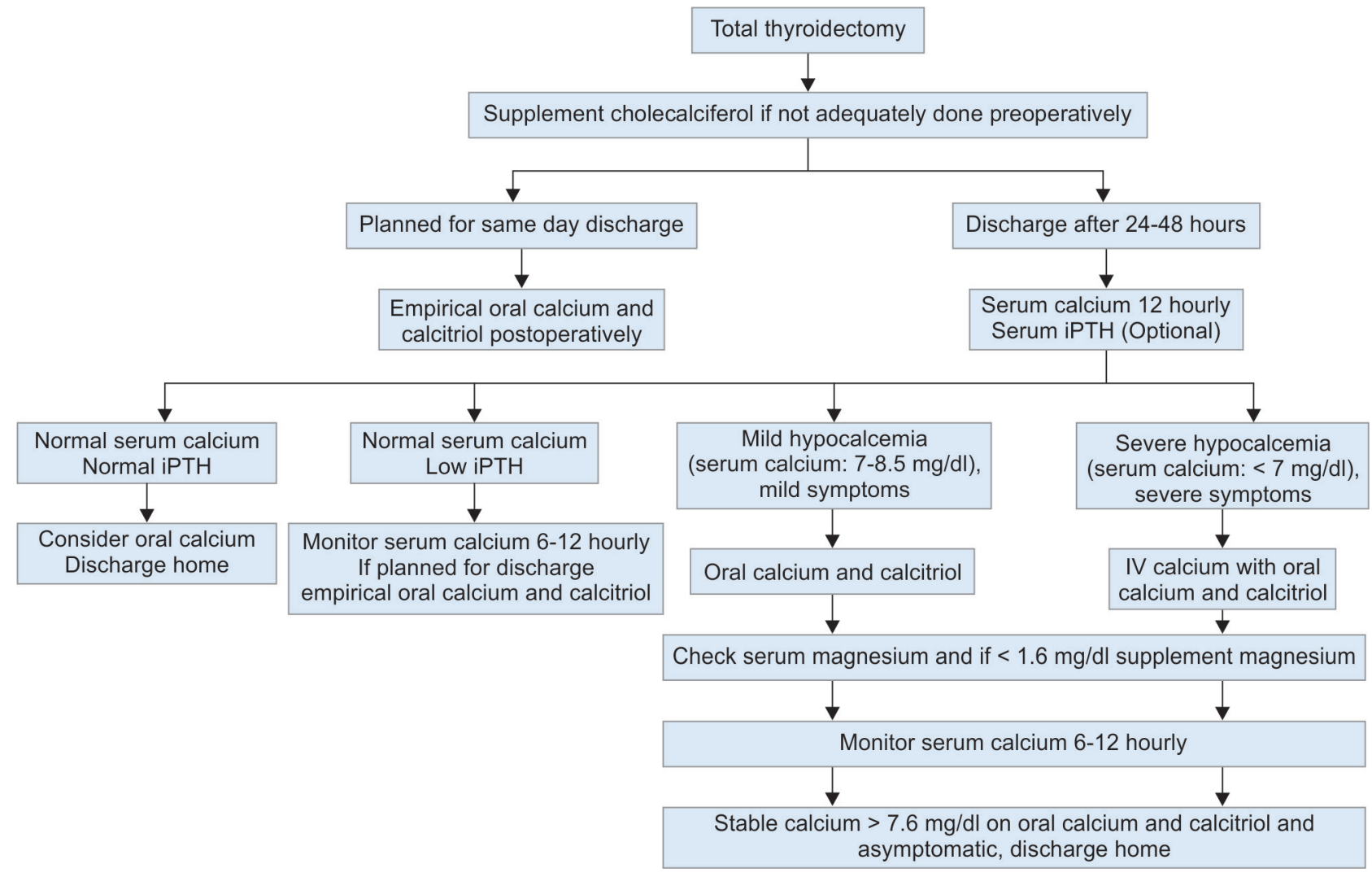




\section{SUMMARY}

The occurrence of hypocalcemia postthyroidectomy is a menacing condition and can be permanent in severe forms. The extent of surgery, presence of Graves' disease, technique of surgery, and the presence of preoperative vitamin $\mathrm{D}$ deficiency have all been proven to play a role in increasing the risk of postoperative hypocalcemia. With the increasing trend of day-care surgeries and early discharge of patients postsurgery, the need of the hour is to evaluate for possible markers to aid in early prediction of postoperative hypocalcemia. Preoperative vitamin D levels, pre- and postoperative iPTH measurement, and evaluation of trend of calcium changes postoperatively can all aid in the prediction of subsequent hypocalcemia. This can aid in selecting the patients at risk for developing hypocalcemia, in order to discharge calcium and active vitamin D replacement and to follow up accordingly.

\section{REFERENCES}

1. Demeester-Mirkine N, Hooghe L, Van Geertruyden J, De Maertelaer V. Hypocalcemia after thyroidectomy. Arch Surg 1992 Jul;127(7):854-858.

2. Shaha AR, Jaffe BM. Parathyroid preservation during thyroid surgery. Am J Otolaryngol 1998 Mar-Apr;19(2):113-117.

3. Schwartz AE, Clark OH, Ituarte P, Lo Gerfo P. Therapeutic controversy: thyroid surgery-the choice. J Clin Endocrinol Metab 1998 Apr;83(4):1097-1105.

4. Baldassarre RL, Chang DC, Brumund KT, Bouvet M. Predictors of hypocalcemia after thyroidectomy: results from the Nationwide Inpatient Sample. ISRN Surg 2012 Jul;2012:838614.

5. Mehanna HM, Jain A, Randeva H, Watkinson J, Shaha A. Post-operative hypocalcemia-The difference a definition makes. Head Neck 2010 Mar;32(3):279-283.

6. Chadwick D, Kinsman R, Walton P, Systems DC. The British Association of Endocrine and Thyroid Surgeons. Fourth National Audit. Henley-on-Thames: Dendrite Clinical Systems Ltd; 2012.

7. Thomusch O, Machens A, Sekulla C, Ukkat J, Brauckhoff M, Dralle $\mathrm{H}$. The impact of surgical technique on post-operative hypoparathyroidism in bilateral thyroid surgery: a multivariate analysis of 5846 consecutive patients. Surgery 2003 Feb;133(2):180-185.

8. Bergenfelz A, Jansson S, Kristoffersson A, Mårtensson H, Reihnér E, Wallin G, Lausen I. Complications to thyroid surgery: results as reported in a database from a multicenter audit comprising 3,660 patients. Langenbecks Arch Surg 2008 Sep;393(5):667-673.

9. Edafe O, Antakia R, Laskar N, Uttley L, Balasubramanian SP. Systematic review and meta-analysis of predictors of postthyroidectomy hypocalcaemia. Br J Surg 2014 Mar;101(4): 307-320.

10. Kakava K, Tournis S, Papadakis G, Karelas I, Stampouloglou P, Kassi E, Triantafillopoulos I, Villiotou V, Karatzas T. Postsurgical hypoparathyroidism: a systematic review. In Vivo 2016 May-Jun;30(3):171-179.

11. Witteveen JE, van Thiel S, Romijn JA, Hamdy NA. Hungry bone syndrome: still a challenge in the post-operative management of primary hyperparathyroidism: a systematic review of the literature. Eur J Endocrinol 2013 Feb;168(3): R45-R53.

12. Dembinski TC, Yatscoff RW, Blandford DE. Thyrotoxicosis and hungry bone syndrome-a cause of posttreatment hypocalcemia. Clin Biochem 1994 Feb;27(1):69-74.

13. Chisthi MM, Nair RS, Kuttanchettiyar KG, Yadev I. Mechanisms behind post-thyroidectomy hypocalcemia: interplay of calcitonin, parathormone, and albumin-a prospective study. J Invest Surg 2017 Aug;30(4):217-225.

14. Bourrel C, Uzzan B, Tison P, Despreaux G, Frachet B, Modigliani E, Perret GY. Transient Hypocalcemia after thyroidectomy. Ann Otol Rhinol Laryngol 1993 Jul;102(7):496-501.

15. Karamanakos S, Markou KB, Panagopoulos K, Karavias D, Vagianos CE, Scopa CD, Fotopoulou V, Liava A, Vagenas K. Complications and risk factors related to the extent of surgery in thyroidectomy. Results from 2,043 procedures. Hormones (Athens) 2010 Oct-Dec;9(4):318-325.

16. Erbil Y, Barbaros U, Salmaslioğlu A, Yanik BT, Bozbora A, Özarmağan S. The advantage of near-total thyroidectomy to avoid post-operative hypoparathyroidism in benign multinodulargoiter. Langenbecks Arch Surg 2006 Nov;391(6): 567-573.

17. Chisholm EJ, Kulinskaya E, Tolley NS. Systematic review and meta-analysis of the adverse effects of thyroidectomy combined with central neck dissection as compared with thyroidectomy alone. Laryngoscope 2009 Jun;119(6): 1135-1139.

18. Nair CG, Babu MJ, Menon R, Jacob P. Hypocalcaemia following total thyroidectomy: An analysis of 806 patients. Indian J Endocr Metab 2013 Mar;17(2):298-303.

19. Percival RC, Hargreaves AW, Kanis JA. The mechanism of hypocalcemia following thyroidectomy. Acta Endocrinol (Copenh) 1985 Jun;109(2):220-226.

20. See AC, Soo KC. Hypocalcemia following thyroidectomy for thyrotoxicosis. Br J Surg 1997 Jan;84(1):95-97.

21. Yamashita H, Noguchi S, Murakami I, Uchino S, Watanabe S, Ohshima A, Toda M, Yamashita H, Kawamoto H. Predictive risk factors for post-operative tetany in female patients with Graves' disease. J Am Coll Surg 2001 Apr;192(4):465-468.

22. Pesce CE, Shiue Z, Tsai HL, Umbricht CB, Tufano RP, Dackiw AP, Kowalski J, Zeiger MA. Post-operative hypocalcemia after thyroidectomy for Graves' disease. Thyroid 2010 Nov;20(11):1279-1283.

23. Wingert DJ, Friesen SR, Iliopoulos JI, Pierce GE, Thomas JH, Hermreck AS. Post-thyroidectomy hypocalcemia. Incidence and risk factors. Am J Surg 1986 Dec;152(6):606-610.

24. Welch KC, McHenry CR. Total thyroidectomy: is morbidity higher for Graves' disease than nontoxic goiter? J Surg Res 2011 Sep;170(1):96-99.

25. Shih ML, Lee JA, Hsieh CB, Yu JC, Liu HD, Kebebew E, Clark OH, Duh QY. Thyroidectomy for Hashimoto's thyroiditis: Complications and associated cancers. Thyroid 2008 Jul;18(7):729-734.

26. Kebsch A, Settmacher U, Lesser T. Bilateral truncal ligation of the inferior thyroid artery during bilateral subtotal thyroidectomy causes a decrease in parathormone without clinically manifest hypoparathyroidism: a randomized clinical trial. Eur Surg Res 2015 Oct;55(3):141-150.

27. Sosa JA, Bowman HM, Tielsch JM, Powe NR, Gordon TA, Udelsman R. The importance of surgeon experience for clinical and economic outcomes from thyroidectomy. Ann Surg 1998 Sep;228(3):320-330. 
28. Toneto MG, Prill S, Debon LM, Furlan FZ, Steffen N. The history of the parathyroid surgery. Rev Col Bras Cir 2016 May-Jun;43(3):214-222.

29. Ambe PC, Wassenberg DR. Is sutureless thyroid surgery safe in the hands of surgical trainees. A single centre retrospective study. BMC Res Notes 2016 Feb;9:118.

30. Sperlongano P, Sperlongano S, Foroni F, De Lucia FP, Pezzulo C, Manfredi C, Esposito E, Sperlongano R. Postoperative hypocalcemia: assessment timing. Int J Surg 2014 May;12(Suppl 1):S95-S97.

31. Alia P, Moreno P, Rigo R, Francos JM, Navarro MA. Postresection parathyroid hormone and parathyroid hormone decline accurately predict hypocalcemia after thyroidectomy. Am J Clin Pathol 2007 Apr;127(4):592-597.

32. Higgins KM, Mandell DL, Govindaraj S, Genden EM, Mechanick JI, Bergman DA, Diamond EJ, Urken ML. The role of intraoperative rapid parathyroid hormone monitoring for predicting thyroidectomy-related hypocalcemia. Arch Otolaryngol Head Neck Surg 2004 Jan;130(1):63-67.

33. McLeod IK, Arciero C, Noordzij JP, Stojadinovic A, Peoples G, Melder PC, Langley R, Bernet V, Shriver CD. The use of rapid parathyroid hormone assay in predicting post-operative hypocalcemia after total or completion thyroidectomy. Thyroid 2006 Mar;16(3):259-265.

34. Lombardi CP, Raffaelli M, Princi P, Dobrinja C, Carrozza C, Di Stasio E, D'Amore A, Zuppi C, Bellantone R. Parathyroid hormone levels 4 hours after surgery do not accurately predict post-thyroidectomy hypocalcemia. Surgery 2006 Dec;140(6):1016-123, discussion 1023-1025.

35. NoordzijJP, LeeSL, Bernet VJ, Payne RJ, Cohen SM, McLeod IK, Hier MP, Black MJ, Kerr PD, Richards ML, et al. Early prediction of hypocalcemia after thyroidectomy using parathyroid hormone: an analysis of pooled individual patient data from nine observational studies. J Am Coll Surg 2007 Dec;205(6):748-754.

36. Del Rio P, Arcuri MF, Ferreri G, Sommaruga L, Sianesi M. The utility of serum PTH assessment 24 hours after total thyroidectomy. Otolaryngol Head Neck Surg 2005 Apr;132(4): 584-586.

37. Puzziello A, Gervasi R, Orlando G, Innaro N, Vitale M, Sacco R. Hypocalcaemia after total thyroidectomy: could intact parathyroid hormone be a predictive factor for transient post-operative hypocalcemia? Surgery $2015 \mathrm{Feb} ; 157(2)$ : 344-348.

38. Kamer E, Unalp HR, Erbil Y, Akguner T, Issever H, Tarcan E. Early prediction of hypocalcemia after thyroidectomy by parathormone measurement in surgical site irrigation fluid. Int J Surg 2009 Oct;7(5):466-471.
39. Erbil Y, Bozbora A, Ozbey N, Issever H, Aral F, Ozarmagan S, Tezelman S. Predictive value of age and serum parathormone and vitamin $\mathrm{d} 3$ levels for post-operative hypocalcemia after total thyroidectomy for nontoxic multinodulargoiter. Arch Surg 2007 Dec;142(12):1182-1187.

40. Tredici P, Grosso E, Gibelli B, Massaro MA, Arrigoni C, Tradati N. Identification of patients at high risk for hypocalcemia after total thyroidectomy. Acta Otorhinolaryngol 2011 Jun;31(3):144-148.

41. Gulluoglu BM, Manukyan MN, Cingi A, Yegen C, Yalin R, Aktan AO. Early prediction of normocalcemia after thyroid surgery. World J Surg 2005 Oct;29(10):1288-1293.

42. Stack BC Jr, Bimston DN, Bodenner DL, Brett EM, Dralle H, Orloff LA, Pallota J, Snyder SK, Wong RJ, Randolph GW. American association of clinical endocrinologists and American College of Endocrinology disease state clinical review: post-operative hypoparathyroidism-definitions and management. Endocr Pract 2015 Jun;21(6):674-685.

43. Zhu J, Tian W, Xu Z, Jiang K, Sun H, Wang P, Huang T, Guo Z, Zhang H, Liu S, et al. Expert consensus statement on parathyroid protection in thyroidectomy. Ann Transl Med 2015 Sep;3(16):230.

44. Wang L, Yang D, Lv JY, Yu D, Xin SJ. Application of carbon nanoparticles in lymph node dissection and parathyroid protection during thyroid cancer surgeries: a systematic review and meta-analysis. Onco Targets Ther 2017 Feb;10:1247-1260.

45. Halsted WS, Evans HM. The Parathyroid Glandules. Their blood supply and their preservation in operation upon the thyroid gland. Ann Surg 1907 Oct;46(4):489-506.

46. Revelli L, Damiani G, Bianchi CB, Vanella S, Ricciardi W, Raffaelli M, Lombardi CP. Complications in thyroid surgery. Harmonic Scalpel, Harmonic Focus versus Conventional Hemostasis: a meta-analysis. Int J Surg 2016 Apr;28(Suppl 1): S22-S32.

47. Zhang L, Li N, Yang X, Chen J. A meta-analysis comparing the outcomes of LigaSure Small Jaw versus clamp-and-tie technique or Harmonic Focus Scalpel in thyroidectomy. Medicine (Baltimore) 2017 Mar;96(11):e6141.

48. Palermo A, Mangiameli G, Tabacco G, Longo F, Pedone C, Briganti SI, Maggi D, Vescini F, Naciu A, Lauria Pantano A, et al. PTH(1-34) for the primary prevention of posthyroidectomy hypocalcemia: the THYPOS trial. J Clin Endocrinol Metab 2016 Nov;101(11):4039-4045.

49. Mishra PE,Schwartz BL,Sarafoglou K,HookK, Kim Y,Petryk A. Short-term PTH(1-34) therapy in children to correct severe hypocalcemia and hyperphosphatemia due to hypoparathyroidism: two case studies. Case Rep Endocrinol 2016 Oct;2016:6838626. 